


\title{
ESTADOS FALIDOS, COMPANHIAS MILITARES PRIVADAS E COLÔMBIA: REPERCUSSÕES POLÍTICAS DO EMPREGO DE SOLDADOS CONTRATADOS NA AMÉRICA DO SUL
}

\section{Fernando Luz Brancoli ${ }^{1}$}

\begin{abstract}
Resumo: O presente artigo aponta as modificações ocasionadas pela utilização por Estados Fracos de Companhias Militares Privadas, sob a luz dos conceitos que historicamente caracterizam o sistema vesfaliano de países, principalmente o de monopólio estatal do uso da força. Para isso, realiza-se um estudo empírico nas transformações ocasionadas por essas Companhias, no âmbito do Plano Colômbia, neste país sul americano. Representantes do processo de liberalização econômica da década de 90 e do conseqüente processo de privatização, as Indústrias Privadas Militares estão presentes atualmente em cerca de 190 países dos cincos continentes. Utilizadas por seu relativo baixo preço e reduzido custo político, comparados aos exércitos convencionais, o crescimento dessas companhias é notável, chegando a casos em que os mercenários representando nações soberanas são mais numerosos nas áreas de guerra do que os soldados estatais. $\mathrm{O}$ estudo de tais questões é uma ferramenta importante para o entendimento dos novos temas envolvendo conflitos no mundo pós-Guerra Fria.
\end{abstract}

Palavras-chave: Segurança Internacional, Soberania, Indústrias Militares Privadas.

Resumen: Este artículo señala lãs modificaciones causadas por el uso de los débiles Estados Compañías Militares Privadas, a la luz de los conceptos que caracterizan El sistema históricamente vesfaliano países, especialmente el monopolio estatal de la fuerza. Para ello, hacemos un estúdio empírico sobre las transformaciones causadas por estas empresas, bajo el Plan Colombia, este país sudamericano. Representantes del proceso de liberalización econômica de los años 90 y el consiguiente proceso deprivatización, la industria militar privada están presentes en aproximadamente 190 países de los cinco continentes. Utilizado por su precio relativamente bajo y de bajo costo político, frente a los ejércitos convencionales, El crecimiento de estas empresas es notable casos, alcanzando en el que los mercenários representan a nacion es soberanas son más numerosos em las zonas de guerra que el estado de los soldados. El estúdio de esas cuestiones es una herramienta importante para comprender los problemas nuevos que aparezcan conflictos en el mundo post-Guerra Fría.

Palabras-clave: seguridad internacional, soberanía, industria militar privada.

Abstract: This article points out the modifications caused by the use of Private Military Companies by Weak States, in light of the concepts that historically characterize the Westphalian system, especially the state monopoly of force. For this, we will perform an empirical study on the transformations caused by these companies, under Plan Colombia, in this south American country. Representatives of the economic liberalization process of the 90 s, the private military industry are currently present in approximately 190 countries on five continents. Used by its relatively low price and political cost, compared to conventional armies, the growth of these companies is remarkable, reaching cases in which the mercenaries representing sovereign nations are more numerous in areas of war than the regular soldiers. The study of such issues is an important tool for the understanding of new issues involving conflicts in the post-Cold War world.

Key-words: International Security, Sovereignty, Private Military Industry

\footnotetext{
${ }_{1}$ Mestrando em Estudos Estratégicos pela Universidade Federal Fluminense (UFF), especialista em Relações Internacionais pela Fundação Getúlio Vargas (FGV)e em Direito Internacional pela Hague Law School, Bacharel em Jornalismo pela Universidade do Estado do Rio de Janeiro (UERJ)
} 


\section{INTRODUÇÃO}

Em 1513, o italiano Niccolò Machiavelli já alertava aos líderes feudais sobre a utilização de mercenários em conflitos, descrevendo-os como aliados perigosos e afirmando que o governante que tem o seu reino apoiado por essas tropas jamais estará seguro. Guardando as devidas proporções, quase quinhentos anos depois a questão se torna recorrente, com nações modernas usando forças privadas de segurança para os mais variados fins.

Neste paper, foca-se no emprego de soldados contratados no âmbito do 'Plano Colômbia'. Criado nos anos 2000 pelos Estados Unidos, o tratado foi considerado, em janeiro de 2009 pelo presidente colombiano Álvaro Uribe, como o "divisor de águas" que garantia a sobrevivência do país sul-americano (EL PAÍS, 2009, p.22). A afirmação dá a dimensão desta questão neste país Sul-Americano, além da importância dos americanos na conjuntura. Contudo, apesar de pouco divulgada, grande parte da ajuda dos EUA é dada através das Companhias Militares Privadas (CMPs), denominadas muitas vezes como Neomercenários (SINGER, 2008, p.5).

O presente artigo aborda esse caso, focando principalmente nas modificações provocadas por esses agentes nas questões envolvendo características pétreas do Estado. Primeiramente, aponta-se uma breve definição do conceito de soberania, com foco no monopólio estatal do uso da força. Após isso, apresentam-se as principais características das CMPs, focando em suas idiossincrasias. Por último, o artigo analisa o Plano Colômbia e sua relação com os Neomercenários.

Para a formulação deste paper, foram empregadas análises de documentos oficiais, tanto dos Estados Unidos quanto da Colômbia, além de apreciação da literatura acadêmica especializada. Somam-se a esses pontos entrevistas realizadas em Bogotá - entre abril e junho de 2010 - com políticos e membros das Forças Armadas colombianas.

\section{BREVE TRATADO DA SOBERANIA E SEUS PRESSUPOSTOS HISTÓRICOS}

Desde a criação dos princípios básicos da arquitetura moderna do sistema internacional, instituídos no período subjacente ao Tratado de Vestfália, a soberania Estatal é vista notadamente como umas das principais características da estrutura institucional vigente. Desenhada inicialmente como método para impedir a criação de uma nação com objetivos expansionistas, a atribuição da soberania regula princípios genéricos básicos paras as nações, mantém o sistema internacional coeso e minimamente funcional, além de conceder poderes únicos para os Estados (MAGNOLI, 2008). 
Pode-se definir soberania como o arcabouço de normas personificadas pelas nações. Jackson e Sørensen (2007) assinalam que:

A soberania é a independência política que um Estado usufrui com relação a outros. O governo tem autoridade suprema para impor a lei sobre seu território.

Além de, supostamente, colocar as nações no mesmo nível, o princípio de soberania também é posto como um pré-requisito para se pertencer a Ordem Internacional, por ser visto justamente como a mais importante característica do Estado. Como explica Vattel:

[Os direitos dos Estados soberanos] são exatamente os mesmos dos demais Estados. (...) Para que uma nação tenha o direito de participar imediatamente nessa grande sociedade, é suficiente que ela seja verdadeiramente soberana e independente, ou seja, que se governe por si mesma. (...) De todos os direitos que uma nação pode possuir, aquele que, sem dúvida é o mais precioso é a soberania (VATTEL, 2008).

O Estado seria então a última e absoluta autoridade da comunidade política, responsável por manter a nação, através da soberania, além de perpetuar a independência externa, a supremacia interna e a identidade nacional (HINSLEY, 1986).

Atualmente regulamentada pela Carta das Nações Unidas, o princípio da soberania e igualdade entre as nações é estabelecido como eixo norteador da organização mundial (JACKSON, 2007). A Corte Internacional de Justiça, por exemplo, aponta que "entre Estados independentes, respeito pela soberania é a fundação essencial das relações internacionais" ${ }^{2}$.

Desta forma, o desenho do Sistema Internacional está integralmente vinculado a princípios básicos que regulam o relacionamento de nações soberanas. Essa afirmação se sustenta pelo fato de que mesmo questões que, em tese, acarretariam no desgaste dessas relações - como conflitos interestatais - estariam submetidas a tais princípios.

A soberania externa compreende vários direitos, entre os quais se salientam: o de ajustar tratados ou convenções, o de legação ou de representação, o de fazer a guerra e a paz (ACCIOLY, 2000, grifo meu).

Partindo desta premissa, pode-se ainda se estimar que os Estados são os únicos e legítimos formadores de um exército nacional, que servirá para manutenção da ordem em seu território e proteção do país internacionalmente. Com base nessa

2 Idem, 2007, p. 209. 
análise, se faz necessário apontar três características internas básicas dos Estados Modernos, que corroboram essa questão, conforme apresentado por Raphael:

(...) um território geográfico definido e reconhecido internacionalmente; jurisdição universal e compulsória dentro dos limites territoriais reconhecidos e monopólio legítimo do uso da força e da violência (RAPHAEL, 2007).

Estabelece-se, deste modo, que as nações soberanas são as únicas utilizadoras legítimas da força, seja dentro do seu território ou contra outra nação, em um momento de guerra. Apesar do nítido paradoxo, já que durante um conflito um Estado estaria violando a soberania de outro, se tem um princípio norteador, no qual são apresentadas nítidas acepções para as nações e quais são as características que podem ser inscritas nelas.

Esse artigo pretende-se centrar no terceiro princípio apresentado por Accioly, o monopólio do uso da violência através da soberania externa. Apresentada como uma das características do Estado moderno, essa exclusividade é justificada, já que através da "virtude do mandato ou da permissão [os Estados promoveriam] as leis" (WEBER, 2002). Percebe-se novamente o princípio pelo qual apenas as nações soberanas estão aptas a observar corretamente as leis, além de legitimarem a sua utilização.

A análise dessas questões demonstra a tentativa de normalização do sistema internacional. Os Estados seriam os promovedores da justiça para seus povos, apontando novamente que todas as possíveis ações da Ordem Internacional, anárquica por natureza - no sentido de não haver uma liderança global - estão nas mãos dos países. Cabem às nações, autênticas e exclusivas jogadoras do tabuleiro global, comandar o destino das populações, em tempos de guerra ou de paz.

Apenas o Estado tem reconhecida autoridade e poder para exigir que as pessoas coloquem suas vidas em jogo, levá-las para as forças armadas ou para defender os interesses em comum da população (BROWN, 1995)

\section{NOVOS PARADIGMAS}

Após essa explanação sobre o conceito clássico de soberania, se tem necessidade de apresentar fatores que promovem erosões nas noções recorrentes do direito de governar um determinado território e a população que nele reside (THOMSON, 1995).

Desta forma, se tem a necessidade de abordar questões históricas e metodológicas que possam indicar os motivos para essas deformações. Durante a 
Guerra Fria, esta suposta independência entre as nações, principalmente as grandes potências, EUA e URSS, era sempre citada como forma de manutenção da paz. Com a queda do muro de Berlim e a subseqüente desintegração da União Soviética, o sistema internacional se deparou com novos desafios, como o número crescente de novos países e a ascensão dos Estados Unidos como o hegemon unipolar.

Essa nova configuração motivou um número cada vez maior de pesquisadores a realizar análises do sistema nas quais a soberania já não seria um conceito tão sólido para se analisar o panorama internacional. Segundo Jackson e Sørensen:

As forças de mercado globais atravessam as fronteiras com mais facilidade e afetam as economias nacionais de formas sem precedentes. Preocupações ecológicas, sistemas de comunicação global, armas nucleares, terrorismo, comércio de drogas, tudo isso e bem mais são exemplos de atividades e forças que ignoram limites territoriais e questionam antigas noções de Estados soberanos autônomos (Idem, 2007).

Com essas modificações, vozes dissonantes, principalmente em relação aos direitos humanos e dos cidadãos, começaram a se levantar. Em 1992, Boutros BroutrosGhali, então Secretário-geral das Nações Unidas afirmou que a época da soberania absoluta havia acabado. Sete anos depois, o colega Kofi Annan escreveu uma matéria descrevendo duas soberanias, a do indivíduo e das nações (ANNAN, 1999). Annan vai mais longe, afirmando que a inicial era mais significante que a segunda, que o indivíduo era mais importante que as nações e que seu bem-estar deveria se sobrepor às noções clássicas de mando dos Estados.

Outro ponto importante conceito a se abordar é o de Estados-fracos. Com a independência de inúmeras províncias no pós-Guerra Fria e o abandono de áreas antes consideradas estratégicas - como setores da África - ocorreu o desmantelamento de nações, que não conseguiram se manter sem auxílio externo. Considerados Estados fracos, onde o governo tem pouco ou nenhum controle sobre o que ocorre em seu território, a supressão da soberania nessa estrutura bem vista pelos atores nacionais, como em casos de auxílio econômico.

As suposições tradicionais acerca de soberania não se aplicam aos Estados fracos, uma vez que estes precisam de um tratamento especial e preferencial do mundo desenvolvido. (...) [Os Estados fracos] são muitas vezes obrigados a conseguir o que querem dos países mais ricos e fortes (JACKSON, 2003).

Finalmente, apresentam-se os desafios dos controles dos meios de violência do mundo pós- Guerra Fria. Com o fim da disputa bipolar, ficou cada vez mais difícil para 
os Estados, principalmente os EUA, justificarem internamente a dispendiosa manutenção dos soldados convencionais. Além disso, ocorreu o fim da ameaça constante provocada pelo "inimigo vermelho", reduzindo-se os motivos para se manter grandes fatias do orçamento com gastos militares. Como solução a essa questão surgem os neomercenários.

\section{NEOMERCENÁRIOS}

Como abordado anteriormente, o fim da Guerra Fria provocou mudanças estruturais nas questões envolvendo a utilização das Forças Armadas e o emprego da violência internacionalmente. A indústria de segurança mundial não foi poupada pela onda de liberalismo nos anos 1990, e desse fenômeno surgem as Companhias Militares Particulares (CMPs na sigla em inglês), como bem descreve Singer:

CMPs são organizações com fins lucrativos que oferecem serviços profissionais intrinsecamente relacionados com conflitos. Elas são corporações que se especializam na provisão de habilidades militares - incluindo operações em combates táticos, planejamento estratégico, análise e coleta de inteligência, suporte em operações, treinamento de tropas e assistência técnica a militares (SINGER, 2007, p.189).

A utilização dessas organizações faz parte de um processo muito maior, denominado "privatização da segurança" (JOSÉ, 2007, p. 76), que assolou praticamente todo o mundo. A redução da participação do Estado em áreas de segurança é explicada por Singer a partir de três pontos. O primeiro seria o vácuo criado na arquitetura da segurança mundial com o fim da Guerra Fria. Com o encerramento das pressões das grandes potências, inúmeros conflitos internos eclodiram. Por sua vez, os países grandes e médios que, durante o sistema bipolar, interviam em conflitos estratégicos, não se alinham mais automaticamente para a resolução desses problemas. Com isso, a necessidade do emprego da força por pequenas nações aumentou consideravelmente.

O segundo ponto seria a revolução tecnológica das batalhas. O campo de combate moderno estaria destinado aos grandes aparatos científicos, controlados a distância ou com inteligência artificial. Com isso, a necessidade de conhecimento técnico é cada vez maior nos meios militares, o que obriga as Forças Armadas a contratar especialistas privados, já que não tem capacidade de abranger todos os especialistas em seu meio. 
A terceira justificativa seria a tendência normativa pela privatização e pelo mercado-livre, gerada pela queda da URSS e pela bancarrota das nações do Leste Europeu, comparadas ao suposto bem-estar das nações do lado ocidental, que teriam adotado a livre competição. A redução do espaço público e a implementação do Estado mínimo foram postos como dogmas e, em muitos setores, a privatização foi vista como solução para a melhoria dos serviços prestados.

Como efeito ilustrativo, o crescimento das CMPs, que são formadas basicamente por ex-militares dos mais diversos países, fez com que os Estados Unidos gastassem mais de 300 bilhões de dólares, entre 1994 e 2002 com os Neomercenários (RENOU, 2005: p.231). Enquanto o número de soldados convencionais americanos diminuiu nos últimos vinte anos, os gastos em contratos com Companhias particulares aumentaram exponencialmente (SCHAHILL, 2003, p.344). Estima-se, por exemplo, que só em dezembro de 2004 as agências prestadoras de serviço cobraram mais de 866 milhões de dólares no Iraque. Por sua vez, no Reino Unido, a indústria militar particular emprega mais do que a estatal (KOBRIN, 1998, p.43).

\section{PANORAMA HISTÓRICO E BENEFÍCIOS}

O emprego de mercenários não é uma inovação na história humana. De fato, a formação de um exército nacional e estatizado é uma novidade nas relações humanas. Como aponta Jeffrey Herbst (1999), "a utilização de particulares em uso de violência era um aspecto rotineiro nas relações internacionais antes do século XX”.

Contudo, as CMPs usam toda sua força para se distanciar dos antigos soldados de aluguel. Enquanto a Convenção de Genebra, de 1949, descreve os mercenários como "pessoas recrutadas para um conflito armado, por um país que não é o seu e movidas apenas pela ganância pessoal3", as Companhias Militares particulares ressaltam que não procuram atuar diretamente no conflito, agindo apenas em ações de reconhecimento e de defesa.

Outra característica importante dessas corporações é que são formatadas como empreendimentos formais, com uma sede, registros fiscais e são apresentadas como aptas a responder pelos seus atos. Dessa forma, aumenta a legitimação de sua utilização, caracterizada como "auxílio civil”, ao invés de soldados contratados.

[Por serem Companhias formais], elas podem utilizar de complexas manobras das corporações comuns - indo da venda de estoque de uma só vez ao comércio entre Companhias semelhantes - e podem se envolver em uma gama complexa de negociações e contratos. Em

3 Visto em http://www.unhchr.ch/html/menu3/b/91.htm, acessado em 21 de setembro de 2009. 
comparação, os mercenários clássicos tendiam a exigir pagamento em dinheiro vivo e não podiam ser confiáveis a longo prazo (SINGER, 2007, p.67).

Para os Estados é extremamente vantajoso, em certos aspectos, utilizar as CMPs. Em primeiro lugar, os custos em operações de médio prazo são menores (JOSE, 2006, p.120), já que as nações não arcam com despesas no campo, e normalmente pagam um valor fixo pré-estabelecido.

Outra questão importante é o preço político reduzido, já que os mercenários não entram na contagem de soldados mortos. No Iraque as baixas de CMPs são registradas como perdas civis de cidadãos estrangeiros. Mais um ponto importante é que, muitas vezes, os soldados particulares não são da nacionalidade do país contratante. Existem hoje no Iraque, chilenos, sul-africanos e nepaleses defendendo os EUA, através das Companhias Particulares Militares.

Acrescenta-se a esses pontos o fato da utilização de mercenários ser relativamente fácil e direta. Em países democráticos e onde o poder é bastante pulverizado, como nos Estados Unidos, há todo um processo político para se utilizar a violência externamente. Existem discussões e barreiras internas, como a necessidade de se aprovar projetos pelo Legislativo, e externas, com a formalização de alianças com outros Estados.

Com a utilização de CMPs, toda essa cadeia, que em última instância evita a realização de guerras desnecessárias e aumenta o arcabouço para controlá-las, é posta por terra.

Se os exércitos de outros países não desejam se aliar numa 'coalizão de boa vontade, (...) [as CMPs] oferecem outro tipo de solução: a internacionalização das forças militares, com recrutamento de soldados de todo o planeta (SCHAHILL, 2007, p. 199).

Um paradoxo pode, então, se formar, quando países que não desejam participar de um conflito observam seus cidadãos participando deles, através das indústrias mercenárias. Para Michael Ratner, presidente da organização americana Centro de Direitos Constitucionais, "o uso cada vez maior de contratados (...) torna mais fácil começar e lutar uma guerra - necessário apenas o dinheiro, e não a cidadania”. 


\section{FORTALECIMENTO DE ATORES NÃO-ESTATAIS}

O franco crescimento das indústrias militares privadas proporcionou que jogadores mundiais não ligados às nações possam agora contar com segurança e equipamentos equivalente aos dos grandes Estados. Atualmente, muitas Companhias contam com arrecadação maior que muitos países, o que torna o dispendioso financiamento de mercenário um problema fácil de solucionar (JOSÉ, 2005),

Atuando em países que não conseguem proporcionar um nível de segurança aceitável, essas companhias contratam agentes para proteger suas instalações e executivos. No entanto, muitas vezes esses soldados particulares podem se voltar contra a população do próprio Estado, por diversos motivos.

Por exemplo, em 2005, na Nigéria seguranças da petroleira Chevron feriram manifestantes do país que reclamavam melhor divisão dos lucros obtidos com o óleo (RENOU, 2005, p.211).

Ocorre novamente um contra-senso ao se tentar analisar esse ponto sob a ótica da soberania clássica. No cenário, um governo soberano, que supostamente teria o monopólio da utilização da força, concede a uma empresa o direito de explorar seus recursos naturais. Os seguranças externos dessa empresa utilizam de violência contra a população da nação em questão, que estaria reivindicando uma melhor repartição de bens naturais soberanos.

\section{ESTADOS FALIDOS E CMPS}

Além dos pontos abordados até este momento, o fim da Guerra Fria encerrou os benefícios tradicionais para países-satélites, principalmente na África. Tais nações eram alvo, durante o período bipolar, de forte amparo militar e econômico das duas potências, principalmente para manter as áreas de influência. Findo o apoio, tais Estados se viram incapazes de resolver ou mitigar questões internas, como tensões sociais e étnicas, principalmente devido à redução da capacidade de investimento nas Forças Armadas (RAPHAEL, 2007).

Neste contexto, inúmeros governos se voltaram para a iniciativa privada para tentar resolver tais questões, muitas vezes realizando o pagamento por meio de commodities ou através da promessa de utilização futura de bens naturais.

O surgimento dos denominados "Estados falidos é um adequado exemplo que auxilia na compreensão da erosão política e institucional de determinados países, fazendo com que se tornem mais dependentes das ações de atores privados. Uma vez que não existe uma definição clara de quais características comporiam uma nação deste 
tipo, decidiu-se utilizar os tópicos apontados por Buzan e Weaver (2003). Segundo os autores 4 , tais Estados se caracterizariam por uma estrutura pré-Vestfália, com "ilhas" de governo soberano em locais específicos, principalmente próximo aos grandes centros habitacionais. Buzan e Weaver apontam ainda que a presença de 'Senhores da Guerra” ou lideranças não-estatais controlando determinadas porções do território são claros indícios de que a nação perdeu o controle sobre o monopólio do uso da força, podendo ser consideradas falidas 5 .

Um dos grandes méritos da definição desses autores é justamente não anexar o Estado falido necessariamente com desmantelamento econômico ou desagregação completa do sistema estatal. Sendo assim, pode-se expandir tal definição, favorecendo a análise para diversas nações do globo.

Nesse quadro de desagregação do poder central, fica cada vez mais comprometida a capacidade do Estado de exercer uma das funções que o definem prioritariamente: o uso da força para manter a ordem interna e assegurar a defesa externa. Sendo assim, tal quadro de desestruturação política e social promove o enfraquecimento da autoridade central sobre o emprego da força, aumentando ainda mais o escopo - e as chances - de utilização de das CMPs.

Com o crescimento das companhias militares, o papel do Estado na esfera da segurança se tornou desprivilegiado, assim como em outras arenas internacionais, como comércio e finanças ${ }^{6}$.

O dilema dessa utilização em demasia é a perda de controle do Estado para indivíduos particulares, que em seu nome, estão realizando missões que demandam violência. Por exemplo, Singer descreve que no conflito entre Eritréia e Somália, na década de 90, uma companhia militar privada contratada pelo governo trocou de lado durante os combates, por encontrar em um general dissidente um apoio melhor.

É interessante apontar que as nações fracas que contratam tais serviços tendem, em uma primeira etapa, a obter vantagens imediatas após o contrato, tendo em vista as características supracitadas, principalmente o emprego imediato de tropas e o baixo custo. A contratação de CMPs pode assegurar, em um primeiro momento, a possibilidade de defesa territorial, por exemplo, além de obter êxito em se defender de um possível poder interno não-estatal. Entretanto, no longo prazo, essas nações enfrentam dificuldades, principalmente em razão de suas fragilidades estruturais, não

\footnotetext{
4 Ambos citam tais questões para lidar com Estados africanos. Contudo, como irá se demonstrar nesse paper, as características podem ser transferidas para outras nações sem maiores problemas. 5 Página 228

${ }^{6}$ SINGER, op.cit, 2007.
} 
conseguindo restabelecer suas Forças Armadas7, além de se tornarem dependentes de um agente alienígena para a manutenção do seu poder.

O enfraquecimento institucional acaba, com isso, reduzindo de maneira drástica as oportunidades de consolidação de um aparato militar local capaz de promover a estabilidade política, em última instância. Como aponta Percy:

(...) a presença de atores privados armados em contexto de volatilidade política (...) não resulta senão no aparecimento de estruturas paralelas de segurança, inibidoras dos esforços de reconstrução das instituições. ${ }^{8}$

\section{QUESTÕES NORMATIVAS}

Uma das grandes questões envolvendo as CMPs está na falta de acordos internacionais claros que definam como as nações deverão monitorar suas ações. No primeiro ponto, as normas sobre as Companhias Militares Privadas não são absolutas nem há uma concordância global sobre como devem ser consideradas (NEVERS, 2009, p.55). Não há consenso entre as autoridades sobre como responder a este desafio, já que a "Convenção Internacional contra o recrutamento, a utilização, o financiamento e o treinamento de mercenários", aprovada pela ONU em 1989 não foi ratificada por inúmeros países - dentre eles os Estados Unidos.

Como se abordou anteriormente, o I $^{\mathrm{o}}$ Protocolo adicional (1977) às Convenções de Genebra de 12 de agosto de 1949 descreve como mercenário qualquer pessoa:

a) que seja propositalmente recrutada, localmente ou no estrangeiro, para combater em conflito armado;

b) que de fato tome parte direta nas hostilidades;

c) que tome parte nas hostilidades motivado pelo desejo de adquirir lucro pessoal, e para o qual recebeu promessa, por uma das partes em conflito ou em seu nome, de remuneração material claramente superior àquela prometida ou correspondente em grau e funções similares nas forças armadas desta mesma parte;

d) que não seja cidadão de uma parte em conflito, nem residente de um território controlado por uma parte em conflito;

e) que não seja membro das forças armadas de uma parte em conflito; $\mathrm{e}$

f)que não tenha sido enviado por um Estado não-parte em conflito, em missão oficial como membro das forças armadas deste mesmo Estado. (Organização das Nações Unidas, 2006)

\footnotetext{
7 UESSELER, Rolf. "Servants of War: Private Military Corporations and the Profit of Conflict". Soft Skull Press, 2008

8 PERCY, Sarah. "Mercenaries: The History of a Norm in International Relations”. Oxford University Press, , 2007, Kindle Edition, 20\%
} 
As CMPs e seus contratados poderiam ser encaixados nos seis pontos. Entretanto, por afirmarem que atuam apenas para proteção e serviços de defesa, não se engajando efetivamente em ofensivas, alegam que não podem receber tal denominação. Vistas como Companhias Civis, ainda não há uma regra clara de como as companhias mercenárias serão entendidas pelo direito internacional.

A outra questão é sobre o monitoramento das tropas particulares no campo de batalha. Por não estarem inscritas na hierarquia rígida dos exércitos formais, os mercenários costumam se reportar apenas aos centros de comando, o que dificulta a avaliação in loco das ações (PELTON, 2007, p.191). Como apresentado anteriormente, os Estados contratam as CMPs para realizar determinadas ações e buscam, posteriormente, avaliar apenas os resultados - e não como se chegou a eles. Na maioria das vezes, não há pesquisa sobre os quadros permanentes das Companhias, que podem empregar ex-militares oriundos de governos que violam sistematicamente os direitos humanos.

O que se tem, desta maneira, é um Estado repassando o seu monopólio do uso da força em questões de guerra e paz para uma empresa particular, que é pouco avaliada durante sua atividade e que pode, durante seu mandato, realizar ações as quais são parte de uma agenda própria.

\section{'PLANO COLÔMBIA' E MERCENÁRIOS}

Criado em julho de 2000 pelos Estados Unidos, o "Plano Colômbia" destina-se oficialmente a combater a produção e o tráfico de cocaína deste país a América do Sul, atuando também no combate às guerrilhas, como as Forças Armadas Revolucionárias da Colômbia (Farc). O programa já injetou, até 2009, cerca de 1,3 bilhão de dólares, com foco principalmente no campo militar- estratégico (Departamento de Estado dos EUA, 2005)

Deste montante, cerca de 60\% é direcionado a Companhias Privadas de Segurança (BIGWOOD, 2001). É interessante ressaltar, entretanto, que a utilização não é exclusiva às Companhias Privadas de Segurança norte-americanas. Companhias israelenses e francesas também possuem contratos com o país sul-americano (RESTREPO, 2008), além de casos em que as CMPs são contratadas por Companhias privadas para garantir a segurança de executivos. Contudo, o foco desse artigo está sobre as Companhias americanas, pela representatividade dessas no montante total e pela área de atuação. 
Das 23 Companhias que possuem contratos com os Estados Unidos, a maioria está envolvida com o treinamento de tropas, utilização de ferramentas de sensoriamento remoto e auxílio no combate direto à guerrilha, principalmente com a utilização de apoio aéreo. Ao todo, cerca de 800 indivíduos estão atuando diretamente em campo. Deste total, a maioria está contratada pela estadunidense DynCorp, que recebe $25 \%$ de todo a verba destinada para CMPs.

É interessante ressaltar que, segundo o acordo, o número de militares americanos autorizados a trabalhar nas operações anti-narcotráfico na Colômbia foi limitado a 400 indivíduos. Todavia, ao aprovar o plano, em julho de 2000, o Congresso autorizou, além dos militares, a presença de 400 agentes civis de investigação. Como a lei refere-se a cidadãos americanos, o Departamento de Estado e as Companhias como a Dyncorp empregam pessoal da Guatemala, Honduras ou Peru, ultrapassando os limites fixados (AVANT, 2008: 231).

A Dyncorp, por exemplo, utiliza pilotos de helicópteros britânicos, mecânicos especializados do Peru e soldados de campo guatemaltecos.

O curioso sobre esta operação é que os contratados desfrutam da mesma imunidade diplomática dos membros da embaixada americana na Colômbia, não sendo abarcados pela legislação nacional. Há documentos apontando que atos ilegais cometidos por este grupo não podem sequer ser investigados, de acordo com o plano bilateral com Washington (CAPDEVILA, 2008, p.6).

\section{A COLÔMBIA É UM ESTADO FALIDO?}

Ao se comparar os pontos levantados por Buzan e Weaver ao modelo colombiano, notam-se inúmeras confluências. Em primeiro lugar, analisa-se uma dupla erosão do monopólio estatal do uso da força, uma vez que dentro da Colômbia atuam Narcoguerrilhas, que em certos locais possuem inclusive um sistema de impostos 9 , além de ser palco da atuação de CMPs, que estão autorizadas a utilizar o poder militar em seu território. Por não deter o monopólio estatal do uso da força em toda sua jurisdição, pode-se afirmar que este país sul-americano possui bolsões de nãosoberania, onde o Estado não possui a capacidade de agir. Ao se comparar, contudo, com países considerados tipicamente falidos, notam-se gradações constitutivas, sendo necessário, para o futuro, a criação de modelos que abarquem os diferentes níveis de desestruturação do Estado.

É importante, entretanto, ressaltar que tal denominação se dá no caso específico da Colômbia, no qual a combinação de Narcoguerrilheiros e, mais

\footnotetext{
9 HOLLINGSHEAD, Ann. Cocaine: Colombia’s Supply \& Spain’s. Financial Task Force, 2010
} 
recentemente, CMPs gerou áreas cinzas jurídicas e de emprego da força. Deve-se destacar o risco da a utilização destes modelos para se analisar diversos países o que pode acarretar na constatação de que todo e qualquer Estado que possui grupos armados se encontra em tal categoria.

\section{TRANSFORMAÇÃO JURÍDICA}

Além disso, nota-se que o judiciário colombiano não possui, em virtude dos tratados assinados, nenhum tipo de competência para investigar ou punir os contratados. Não é imperativo afirmar que há o fortalecimento da supracitada área de não-soberania em território colombiano. Esses pontos se tornam mais aparentes ao se observar que em 2008 os jornais colombianos noticiaram a morte de 120 pessoas em confrontos diretos com mercenários (EL MERCÚRIO, 2009, E2), as quais não foram investigadas por órgãos nacionais.

Remover estas Companhias de jurisdição penal colombiana implica simultaneamente na invisibilidade e na negação dos direitos das vítimas, materializado especificamente no conhecimento da verdade os atos, o acesso à justiça, e uma reparação integral, o que implica garantindo a não-repetição desses crimes (RESTREPO, 2008, p. 5).

É de suma importância apontar ainda mais uma questão a respeito da utilização das CMPs. A chegada em peso das Companhias militares privadas no cenário internacional provocou uma mudança intrínseca na maneira com que os Estados atuam em relação à mobilização de tropas militares. Os Neomercenários, por estarem disponíveis em pouco tempo para atuação transformaram radicalmente o modo de se fazer guerra. Anteriormente, se demandava tempo e dinheiro para treinar uma tropa de soldados. Agora, com um simples telefonema pode-se ter em seu país uma tropa completa e treinada (RICHEMOND-BARAK 2007, p.98).

O poder econômico pode se tornar poderio militar em muito pouco tempo. Com isso, Estados fracos politicamente, governados a mão-de-ferro e com grandes reservas naturais, como é o caso dos países africanos, podem se tornar, em poucos dias, ameaças para seus vizinhos ou uma potência militar local (JOSÉ, 2007, p.77).

As nações, desta forma, podem realizar operações militares de grande porte sem efetivamente mobilizarem tropas nacionais. Abdicando de sua soberania e exclusividade em exercer a violência, as nações podem acabar perdendo o controle sobre os mercenários que contratavam e que se legitimam. Os governos tendem, com isso, a perder licitude e controle sobre os braços armados. 
Ao aplicar essa análise ao caso colombiano e somar tais questões a porosa fronteira amazônica onde os Neomercenários atuam, é interessante apontar para a possibilidade de o conflito passar ao território dos países vizinhos, como o Brasil. Analisando-se as questões supracitadas, é condição sine qua non os governos da América do Sul iniciem um processo normativo claro no continente, a fim de estabelecer regras vinculantes sobre a utilização de tais Companhias.

\section{CONCLUSÃO}

Após a análise das questões levantadas nesse artigo, pode-se apontar que os grupos privados militares erodem de modo sistemático os conceitos clássicos de soberania do sistema internacional vigente. Os Neomercenários detêm, em inúmeros casos, uma agenda própria, a qual é cumprida sem autorização das autoridades, exercendo a força e violência em nome de uma nação soberana.

Em Estados fracos, entretanto, as Companhias Militares Privadas podem se tornar atores políticos importantes e - como visto neste artigo - efetuarem mudanças significativas na arquitetura local. Os objetivos das Companhias tornam-se desígnios da própria administração central, podendo surtir efeitos catastróficos no planejamento dos Estados. Fica claro ainda que, na maioria das vezes, os benefícios provocados em tais nações, em médio prazo, não compensam os custos, principalmente pela criação de dependência em relação às Companhias.

A utilização das CMPs, como abordado, provoca um paradoxo, já que elementos do Estado, como chefes do Executivo, se fortalecem em certos pontos e outros segmentos das nações perdem poder. $\mathrm{O}$ uso de neomercenários permite que líderes governamentais possam impor restrições ao próprio Estado, como a dificuldade de aprovação de outros poderes e de aceitação pública. Por outro lado, a concessão do monopólio do uso da força para um ator não-estatal faz com que agentes alienígenas da nação exerçam o uso da violência, em nome do país, e muitas vezes com objetivos distintos. Isso promove um sério problema de legitimação da autoridade do país, que pode ser analisado em pesquisas futuras.

O uso dessas Companhias modifica ainda as formas conhecidas de balanço de poder e de transformação de poderio econômico em militar. Os mercenários estão disponíveis em pouco tempo e a quem conseguir pagá-los, o que torna ainda mais atrativa a sua utilização. Um dos problemas, no entanto, é que quando utilizados por Estados fracos, os soldados particulares podem se tornar a força mais poderosa da região, se tornando aptos a moldar a arquitetura local com a utilização da força. Isso ocorre em um cenário no qual não são atores estatais e não detém todas as 
características e prioridades que as nações possuem de acordo com a estrutura clássica das relações internacionais.

No caso do 'Plano Colômbia' a situação é ainda mais peculiar. Por se tratar de Companhias contratadas por um país terceiro, ainda não está claro como a conjuntura irá afetar o resto do continente. De fato, este país da América do Sul está abrindo mão de parte de sua soberania, seja por abrir mão do monopólio da utilização do poderio militar ou mesmo na redução da capacidade de gerir assuntos internos, como a investigação de crimes. Ressalta-se, novamente, a necessidade de se pensar em novos processos normativos vinculantes que abarquem a situação no continente. Apenas a presença de diretrizes claras irá trazer, pelo menos em parte, normalidade para a situação.

\section{BIBLIOGRAFIA}

ANNAN, Kofi, Two sovereignty, Acessado em http://www.un.org/news/ossg/sg/stories/kaecon.html Acesso: 20 de setembro de 2009.

AVANT, Debora, The Market for Force: The Consequences of Privatizing Security, Cambridge University Press, 2005

BIGWOOD, Jeremy. DynCorp in Colombia: Outsourcing the Drug War. Disponível em http://www.corpwatch.org/article.php?id=672. Acesso: em junho de 2010, as 20:00

BROWN, Seyom . New Forces Old Force and the Future of World Politics: Post Cold War Edition (New York, NY: Harper Collins College Publishers), 1995.

CAPDEVILA, Gustavo. Mercenaries At Large in Colombia. Disponível em http://ipsnews.net/news.asp?idnews=45198. Acessado em julho de 2010.

Contemporary Conflict Situations', Jerusalem, 2008

DEPARTAMENTO DE ESTADO DOS EUA. Half of U.S. military aid goes through private contractors, Acessado em http://www.cipcol.org/?p=416 em junho de 2010

EL MERCÚRIO. Companhias Americanas matam mais de 100 civis em confrontos. Página E2, 2009.

EL PAÍS. Uribe afirma que guerra às Farc será vencida. Caderno Internacional, p. 22, 2009.

HERBST, Jeffrey. The Regulation of Private Security Forces.

STREMLAU, John. The Privatisation of Security in Africa. South Africa Institute of International Affairs, 1999

HINSLEY, Francis H. Sovereignty, Cambridge Press, 1986. 
HURRELL, Andrew. On Global Order: Power, Values, and the Constitution of International Society, Kindle Edition- Oxford University Press, 23\%, 2008.

JACKSON, Robert. Sovereignty: The evolution of an idea, Polity, 2007.

JACKSON, Robert, SORENSEN, George. Introdução às Relações Internacionais, Jorge Zahar Editora, 2000.

JOSE, Jim. Transformations in Sovereignty, Political Authority and Capacity in the Governance State, Ed Newcastle University, 2007.

KOBRIN, Stephen. Back to the Future: Neomedievalism and the Postmodern, Journal of International Affairs, 1998.

MAGNOLI, Demetrio. História da Paz. Editora Contexto, 2008.

NAÇÕES UNIDAS. Report of the Working Group on the Use of Mercenaries as a Means of Violating Human Rights and Impeding the Exercise of the Right of People to Self-Determination, acessado em

http://www.unhcr.org/refworld/country,,,MISSION,FJI,45b632e02,4795eacf2,o.html, em setembro de 2009

NEVERS, Renéé De. Private Security Companies and the Laws of War. Sage: Security Dialogue, 2009.

PELTON, Robert Young. Licensed to Kill: Hired Guns in the War on Terror, Three Rivers Press, 2007.

RAPHAEL, David Daiches. Apud JOSE, Jim. Transformations in Sovereignty, Political Authority and Capacity in the Governance State, Ed Newcastle University, 2007.

RESTREPO, José Alvear. Private Security Transnational Enterprises in Colombia. Corporación Colectivo de Abogados, 2008.

RICHEMOND-BARAK, Daphné. Private Military Contractors and Combatancy Status Under International Humanitarian Law, paper presented at the international conference on 'Complementing IHL: Exploring the Need for Additional Norms To Govern Contemporary Conflict Situations’, Jerusalém, 2008.

SCHAHILL, Jeremy. Blackwater: a ascensão do exército mercenário mais poderoso do mundo. Companhia das Letras, 2003.

SINGER, P.W. Corporate Warriors: The Rise of the Privatized Military Industry, Cornell Studies in Security Affairs, 2007.

THOMSON, Janice F. State Sovereignty in International Relations: Bridging the Gap Between Theory and Empirical Research, International Studies Quarely, 1995.

WEBER, Max. Ensaios de Sociologia. São Paulo: Ed. LTC, 2002.

VATTEL, Emer de. O direito das gentes. Prefácio e Tradução: Vicente Marotta Rangel. Brasília: Editora Universidade de Brasília: Instituto de Pesquisa de Relações Internacionais, 2004, p. 104. 